\title{
Salt and blood pressure in Scotland
}

\author{
D G BEEVERS, V M HAWTHORNE, P L PADFIELD
}

\section{Summary and conclusions}

Dietary salt intake and urinary sodium excretion were compared in normotensive and hypertensive subjects in Renfrew, Scotland. All groups had high 24-hour urinary salt excretions, and hypertensive subjects did not eat or excrete more salt than normotensive subjects. The only significant relations found were a lower sodium excretion in hypertensive women than in normotensive women $(p<0.02)$ and a lower urinary sodium concentration in hypertensive men than in normotensive men $(p<0.05)$.

These data provide no support for the hypothesis that dietary salt is a major cause of hypertension.

\section{Introduction}

The hypothesis that excessive salt ingestion may be an important factor in the development of hypertension is based on much indirect evidence but little direct proof. In primitive societies where salt intake is very low raised blood pressure is rarely seen, and blood pressure does not rise with advancing age. ${ }^{1-3}$ In patients with hypertension moderate or severe salt restriction leads to a fall in blood pressure..$^{5}$ Few studies within a single society, however, have shown higher salt intakes in hypertensive than in normotensive subjects, yet the lack of evidence despite the "salt hypothesis" is widely held.

We have assessed salt intake and urinary sodium excretion in an area of Scotland where the prevalence of hypertension is high $^{6}$ and where there is a correspondingly high incidence of coronary heart disease and stroke. who at the time of screening in 1972 had diastolic pressures of 105 $\mathrm{mm} \mathrm{Hg}$ or more or had pressures below this value while receiving treatment for hypertension, having had recorded pressures above 105 $\mathrm{mm} \mathrm{Hg}$. After excluding subjects whose pressures were below $90 \mathrm{~mm}$ $\mathrm{Hg}$ on rescreening 227 patients were left. Of these, 49 either defaulted or died before this study began, and in a further 17 cases it was not considered safe to stop giving diuretics, so these were excluded from the analysis.

Thus 161 hypertensive subjects were eligible for investigation, and 24 -hour urine collections were obtained from $110(68 \cdot 3 \%)$. The normotensive control group comprised 92 subjects representing a $5 \%$ random sample of untreated subjects with diastolic pressures below $90 \mathrm{~mm} \mathrm{Hg}$ at screening. All blood pressures were measured with the London School of Hygiene sphygmomanometer.

All subjects were asked to provide a single 24-hour collection of urine, while taking their normal diet. A simple written instruction sheet was provided. Only those hypertensive subjects who had not taken diuretics for at least 28 days were included. All respondents were later asked to complete a simple questionnaire about their dietary salt, ${ }^{9}$ in which they stated whether they always, sometimes, or never added salt to their food before tasting and whether they preferred salty foods.

Replies to the questionnaire were subdivided into four grades of dietary salt intake.

\section{Results}

Table I shows the 24-hour urinary excretion of sodium, potassium, and creatinine in the hypertensive and normotensive subjects. Hypertensive subjects did not have higher urinary sodium excretions than normotensive subjects, and women with hypertension excreted significantly less sodium than their normotensive controls $(p<0.02)$.

As 24-hour urine collections are often incomplete, urinary sodium

TABLE I-Mean $( \pm S D)$ 24-hour urinary, sodium, potassium, and creatinine excretions, 24-hour urinary volume, urinary sodium concentration, and urinary sodium/g creatinine in male and female normotensive and hypertensive subjects

\begin{tabular}{|c|c|c|c|c|c|}
\hline & & \multicolumn{2}{|c|}{ Men } & \multicolumn{2}{|c|}{ Women } \\
\hline & & $\begin{array}{l}\text { Normotensive } \\
\quad(n=45)\end{array}$ & $\begin{array}{l}\text { Hypertensive } \\
\quad(n=51)\end{array}$ & $\begin{array}{l}\text { Normotensive } \\
\quad(n=47)\end{array}$ & $\begin{array}{l}\text { Hypertensive } \\
\quad(n=59)\end{array}$ \\
\hline 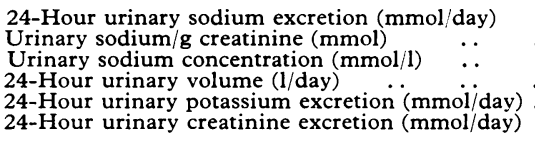 & $\begin{array}{l}\cdots \\
\cdots \\
\cdots \\
\cdots\end{array}$ & $\begin{array}{l}196 \cdot 1 \pm 62 \cdot 0 \\
147 \cdot 9 \pm 48 \cdot 9 \\
134 \cdot 4 \pm 43 \cdot 6 * \\
1 \cdot 69 \pm 0 \cdot 55 \\
46 \cdot 9 \pm 20 \cdot 0 \\
12 \cdot 1 \pm 3 \cdot 4\end{array}$ & $\begin{array}{l}182 \cdot 1 \pm 67 \cdot 2 \\
136 \cdot 9 \pm 69 \cdot 1 \\
115 \cdot 4 \pm 40 \cdot 3 * \\
1 \cdot 54 \pm 0 \cdot 49 \\
47 \cdot 0 \pm 21 \cdot 5 \\
12 \cdot 9 \pm 4 \cdot 0\end{array}$ & $\begin{array}{l}173 \cdot 4 \pm 53 \cdot 6 * * \\
160 \cdot 4 \pm 44 \cdot 3 \\
113 \cdot 2 \pm 33 \cdot 9 \\
1 \cdot 63 \pm 0 \cdot 53 \\
46 \cdot 1 \pm 18 \cdot 8 \\
9 \cdot 7 \pm 2 \cdot 5\end{array}$ & $\begin{array}{l}144 \cdot 4 \pm 59 \cdot 4^{* *} \\
145 \cdot 6 \pm 63 \cdot 2 \\
103 \cdot 0 \pm 41 \cdot 7 \\
1 \cdot 43 \pm 0 \cdot 61 \\
41 \cdot 1 \pm 17 \cdot 6 \\
9 \cdot 2 \pm 2 \cdot 8\end{array}$ \\
\hline
\end{tabular}

\section{Subjects and methods}

The epidemiological study of the 45-64-year-old population of Renfrew, Scotland, has been described elsewhere ${ }^{6}$; subsequently a follow-up clinic was established to study the hypertensive subjects and a random sample of normotensive subjects. ${ }^{8}$

In this analysis the hypertensive group was defined as all subjects

MRC Blood Pressure Unit, Western Infirmary, Glasgow G11 6NT

D G BEEVERS, MD, MRCP, clinical scientist (present address: Dudley Road Hospital, Birmingham B18 7QH)

P L PADFIELD, MB, MRCP, clinical scientist (present address: Gardiner Institute, Western Infirmary, Glasgow)

Cardiorespiratory Unit, Glasgow

V M HAWTHORNE, MD, FRCP, professor (present address: Department of Epidemiology, Ann Arbor, Michigan, USA) excretions were "corrected" to $1 \mathrm{~g}$ of creatinine. After this adjustment no significant differences were observed in urinary sodium excretion; urinary sodium concentrations in hypertensive subjects were if anything lower than that in normotensive subjects. No significant differences were found in urinary potassium concentrations or urinary volumes between men and women, or between hypertensive and normotensive subjects. Important differences between the two sexes were found: men tended to excrete more creatinine and sodium. We therefore could not consider the two sexes together in this analysis.

Not only did hypertensive subjects not excrete more sodium than normotensive subjects but also no correlations were found between blood pressure values and urinary sodium excretions in any hypertensive group studied (men: systolic blood pressure $v 24$-hour urinary sodium excretion, $p=0.25$; diastolic blood pressure $v$ urinary sodium excretion, $p=0.25$; women: systolic blood pressure $v 24$-hour urinary sodium excretion, $\rho=0.04$; diastolic blood pressure $v$ urinary sodium excretion, $p=-0.06)$. The correlations of blood pressure against urinary sodium in the hypertensive subjects were submitted to a 
Spearman's rank correlation analysis, as the data for blood pressure represented only the upper $10 \%$ of the distribution of blood pressure in the whole population. The normotensive data, representing a sample of cases with pressures below $90 \mathrm{~mm} \mathrm{Hg}$, were distributed more normally, so conventional regression analysis was possible. No significant relations were found between sodium excretion and blood pressure in the normotensive subjects (women: systolic blood pressure $v$ 24-hour urinary sodium excretion, $r=0.0558$; diastolic blood pressure $v$ 24-hour urinary sodium excretion, $r=0.0606$; men: systolic blood pressure $v 24$-hour urinary sodium excretion, $r=0.0502$; diastolic blood pressure $v$ 24-hour urinary sodium excretion, $\mathrm{r}=$ $0 \cdot 1298)$

The replies to the questionnaire were graded into four levels of sodium intake according to whether subjects said that they routinely added salt to food before tasting or preferred salty foods. This crude assessment failed to show any relation between dietary salt intake and urinary sodium excretion in normotensive subjects, though some trend was seen in hypertensive subjects (table II). Among men $43 \%$ of the hypertensive and $48 \%$ of the normotensive subjects had higher salt intakes (grades 3 and 4 on questionnaire), while among women $32 \%$ of hypertensive and $29 \%$ of normotensive subjects had higher intakes. This tendency for men to claim to eat more salt was reflected in their higher 24-hour urinary sodium excretions.

TABLE II-Dietary salt grade as assessed from responses to dietary salt questionnaires in male and female normotensive and hypertensive subjects. (Mean 24-hour urinary sodium excretions (mmol/day) are shown in parentheses)

\begin{tabular}{cccccc}
\hline \multirow{2}{*}{ Salt grade } & \multicolumn{3}{c}{ Men } & & \multicolumn{2}{c}{ Women } \\
\cline { 2 - 3 } \cline { 5 - 6 } \cline { 5 - 6 } & Normotensive & Hypertensive & & Normotensive & Hypertensive \\
\hline 1 & $8(202)$ & $16(156)$ & & $25(183)$ & $28(140)$ \\
2 & $12(198)$ & $8(172)$ & & $8(200)$ & $8(146)$ \\
3 & $13(187)$ & $11(209)$ & & $8(138)$ & $11(176)$ \\
4 & $5(200)$ & $9(221)$ & & $4(173)$ & $7(171)$ \\
No reply & $7(201)$ & $7(161)$ & & $2(179)$ & $5(115)$ \\
\hline Total & $45(196)$ & $51(182)$ & & $47(173)$ & $59(144)$ \\
\hline
\end{tabular}

\section{Discussion}

Despite the high prevalence of hypertension in the Renfrew population $(38.9 \%$ of this middle-aged population had diastolic pressures of $90 \mathrm{~mm} \mathrm{Hg}$ of over), this study, like many others, failed to show excess salt ingestion or excretion in subjects with raised blood pressure within a single population. ${ }^{9-12}$ Our study is similar to that of Berglund $e t a l^{13}$ in finding slightly lower urinary sodium excretions in hypertensive subjects than in people with normal pressures.

The Gothenberg group, however, did find positive correlations between urinary salt excretion and blood pressure in normotensive subjects and negative correlations in hypertensive subjects. Although our study was larger than the Gothenberg study, we found no such correlations.

Some studies within a single population have shown greater urinary sodium excretion in hypertensive subjects, ${ }^{4}{ }^{14}$ while others have found higher reported dietary salt intake. ${ }^{9}$ Using a similar questionnaire, however, neither we nor the Framingham group found such a relationship.

Our study, however, does not disprove the salt hypothesis, as we have detected relatively high salt excretions in a population with a high prevalence of hypertension. Generally, societies that take diets high in salt have higher blood pressures than those with low salt intakes. (If the present data were added to such international comparisons they would tend to confirm the salt hypothesis.) International comparisons, however, suffer from the obvious weakness that many other variables may be present to explain differences in blood pressure. Both hypertension and cardiovascular disease tend to be more common in north European countries, where salt and animal-fat consumption are higher, than in southern European countries such as Italy and Greece. Differences in diagnostic categorisation and other environmental and genetic factors may explain some of the reported differences in disease patterns. High salt intake can only be one of many factors causing hypertension; the combination of high salt intake with other environmental influences and a genetic predisposition may cause rasied blood pressure.

The collection of several 24-hour urine samples for each subject might have provided a more reliable estimate of salt intake, although the day-to-day variation in urinary sodium excretion is large even in subjects receiving a fixed dietary salt intake. ${ }^{15}$ The "correction" for creatinine excretion might overcome some of these problems. This technique was used by Parjis et $a l,{ }^{4}$ and an impressive correlation was found between blood pressure and urinary sodium excretion.

The results of our study, however, do not confirm their observations.

This research was aided by a grant from the Renfrewshire King Edward Memorial trust. We thank Sister S M Duncan and Dr C S Nelson for help in running the clinic, and Dr L K Harding for statistical advice.

Requests for reprints should be sent to Dr D G Beevers, Dudley Road Hospital, Birmingham B18 7QH.

\section{References}

${ }^{1}$ Lowenstein FW. Blood pressure in relation to age and sex in the tropics and sub-tropics. A review of the literature and an investigation in two tribes of Brazil Indians. Lancet 1961 ; :389-92.

2 Page LB, Danion A, Moellering RC. Antecedents of cardiovascular disease in six Solomon Island societies. Circulation 1974;49:1132-46.

3 Meneely GR, Batterbee HD. High sodium, low potassium environment and hypertension. Am $\mathcal{F}$ Cardiol 1976;38:768-85.

4 Parjis J, Joossens JV, Van der linden L, Amery AKPC. Moderate sodium restriction and diuretics in the treatment of hypertension. Am Heart $\mathcal{F}$ $1973 ; 85: 22-34$.

5 Morgan T, Adam W, Gillies A, Wilson M, Morgan G, Carney S. Hypertension treated by salt restriction. Lancet 1978;i:227-30.

${ }^{6}$ Hawthorne VM, Greaves DA, Beevers DG. Blood pressure in a Scottish town. $\mathrm{Br} \mathrm{Med} \mathcal{F} 1974$;iii:600-3.

${ }^{7}$ Registrar General for Scotland. Annual report. Part 1. Mortality statistics. Edinburgh: HMSO, 1974.

${ }^{8}$ Beevers DG, Duncan S, Nelson CS, Padfield PL. A blood pressure clinic in a health-centre. Postgrad Med f 1976;52:683-6.

9 Swaye PS, Gifford RW, Berrettoni JN. Dietary salt and essential hypertension. Am $\mathcal{F}$ Cardiol 1972 ;29:33-8.

10 Simpson FO, Waal-Manning HJ, Bolli P, Phelan EL, Shears GFS. Relationship of blood pressure to sodium excretion in a population survey. Clin Sci Mol Med 1978;55:373s-5s.

${ }^{11}$ Dawber TR, Kannel WB, Kagan A, Donabedian RK, McNamara PM, Pearson G. Environmental factors in hypertension. In: Stamler J, Stamler R, et al, eds. Epidemiology of hypertension. New York: Grune and Stratton, 1967.

12 Miall WE. Follow-up study of arterial pressure in the population of a Welsh mining valley. $\mathrm{Br} \mathrm{Med} \mathcal{F} 1959$;ii:1204-10.

13 Berglund G, Wikstrand J, Wallentin I, Wilhelmsen L. Sodium excretion and sympathetic activity in relation to severity of hypertensive disease. Lancet $1976 ; \mathrm{i}: 324-8$.

${ }^{14}$ Morgan $T$, Carney S, Wilson $M$. Inter-relationship in humans between sodium intake and hypertension. Clin Exp Pharmacol Physiol 1975;2: $127-9$.

15 Black DAK, Thomson AE. Day to day changes in sodium and water output with and without posterior pituitary extract. Clinical Science 1951;10:511-20.

ONE HUNDRED YEARS AGO I was called to T E, who had attempted to commit suicide by firing a revolver into his mouth. On examining him, I found a very little blood in the mouth. On washing it out, I found the right side of the tongue charred, and an opening through the right tonsil about the size of a goosequill. On exploring this, my director took an upward and backward course to the transverse process of the first cervical vertebra, and then towards the left. I could detect the bullet firmly impacted in the body of that bone. The man seemed none the worse for the injury. I held a consultation, and we decided that it would be injudicious to attempt to remove the bullet. He was committed to prison, and thus I lost sight of him for ten weeks. He is now in perfect health, and in no way suffers from the bullet, which has never been removed. WALTER Buchanan, Chatham. (British Medical fournal, 1880.) 